\title{
Tribological Investigation of Self-Healing Composites Containing Metal/Polymer Microcapsules
}

\author{
Dawei Sun, ${ }^{1}$ Jianhua Yan, ${ }^{1}$ Xiaoyu Ma, ${ }^{1}$ Mingzhang Lan, ${ }^{1}$ Ziming Wang, ${ }^{1}$ Suping Cui ${ }^{1, *}$ and Jinglei Yang ${ }^{2, *}$
}

\begin{abstract}
The tribological properties of epoxy composites containing metal microcapsules and polymer microcapsules were investigated systematically. Both metal microcapsules and polymer microcapsules showed obvious core shell structures. The diameter of metal microcapsules and polymer microcapsules was $200.7 \pm 44.5 \mu \mathrm{m}$ and $185.2 \pm 44.2 \mu \mathrm{m}$ with a corresponding core fraction of $23.5 \pm 1.3 \mathrm{wt} \%$ and $75.0 \pm 2.1 \mathrm{wt} \%$, respectively. The epoxy composites containing metal microcapsules possessed higher compressive strength than that containing polymer microcapsules, but its compressive modulus remained stable relatively with microcapsule concentrations, comparing with the gradual decrease of compressive modulus of composites containing polymer microcapsules. Besides, the friction coefficient of epoxy composites containing polymer microcapsules (less than 0.1) was several times lower than that of epoxy composites containing metal microcapsules (around 0.55). The friction coefficients of epoxy composites containing polymer microcapsules were decreased under higher microcapsules concentrations, but that of epoxy composites containing metal microcapsules was increased with microcapsules concentrations. Although composites containing metal microcapsules had higher strength and modulus than that containing polymer microcapsules, its wear loss including wear depth and wear width was far more than the composites containing polymer microcapsules under different normal loads and velocities.
\end{abstract}

Keywords: Metal microcapsules; Polymer Microcapsules; Microcapsules tribology; Friction coefficients.

Received: 25 March 2021; Accepted: 12 May 2021.

Article type: Research article.

\section{Introduction}

The corrosion of steel rebars initiated serious cracking of concrete through volume expansion of rust, resulting in serious safety concerns and environmental issues. ${ }^{[1,2]}$ The polymer coating was an efficient method to protect the steel rebars from corrosive environments through barrier function..$^{[3]}$ Moreover, the cost of polymer coatings was decreased gradually with the development of industrial and energy recycling techniques. However, the polymer coatings were easily broken by the abrasion and strike damages, resulting in re-exposure and more serious corrosion of steel rebar.

To retard the abrasion of the polymer, both solid and liquid lubricant were embedded successfully into the polymer matrix for lower friction coefficient. Common solid lubricant fillers included PTFE, $\mathrm{MoS}_{2}$, and graphite. Solid lubricants could form a layer of transfer film with low shear strength at the

\footnotetext{
${ }^{I}$ College of Materials Science and Engineering, Beijing University of Technology, Beijing 100124.

${ }^{2}$ Department of Mechanical and Aerospace Engineering, Hong Kong University of Science and Technology, Hong Kong Special Administrative Region.

*Email: cuisuping@bjut.edu.cn (S.Cui), maeyang@ust.hk (J. Yang)
}

contact interface to reduce the friction coefficient, ${ }^{[4]}$ which could also retard the friction heat and therein weaker thermal softening of the polymer matrix. Normally, PTFE was the most effective to decrease the wear rate of most polymers. ${ }^{[5]}$ Besides, graphite was more effective than $\mathrm{MoS}_{2}$ in reducing polymer wear rate. ${ }^{[6]}$

Besides solid lubricants, liquid lubricants were also used to retard the wear of polymeric materials for outstanding performance. The lubricating performance of the polymeric matrix depended greatly on the compatibility between liquid lubricants and matrix. ${ }^{[7]}$ However, liquid lubricant was not applicable to oil-sensitive and oil-contamination-free materials due to the incompatibility, while encapsulating liquid lubricant within solid shells settled efficiently this problem. Such microcapsules were fabricated and dispersed successfully within the polymeric matrix as self-lubricant materials, which release liquid lubricant automatically to mitigate frictions. Guo et al..$^{\left[{ }^{[7}\right.}$ incorporated microcapsules containing lubricant oil into epoxy composites with a final friction coefficient as low as 0.09 . Recently, isocyanate microcapsules attracted numerous attention due to their capability of simultaneous self-healing ${ }^{[9,10]}$ and self- 
lubricating performances, ${ }^{[11,12]}$ and the friction coefficient of composites containing isocyanate microcapsules $(10 \mathrm{wt} \%)$ could even reach $0.136 .^{[11]}$ Maryam et. al..$^{[13]}$ added linseed oil microcapsules into epoxy coatings, and the friction coefficient of final composites was 0.1 , showed outstanding selflubricating performances. Khun et al..$^{[12,14]}$ prepared successfully self-lubricant materials by embedding liquid wax microcapsules in silicone and encapsulated hexamethylene diisocyanate (HDI) in epoxy resin, obtaining interesting effects. The liquid wax could decrease the friction coefficient of silicone composites to as low as $0.5 .^{[14]}$ Sun et al..$^{[11]}$ applied encapsulated 4,4'-diphenylmethane diisocyanate (HMDI) to achieve the simultaneously self-healing and self-lubricating performance of epoxy composites, whose tribological performance was improved obviously due to higher core fraction and larger microcapsules sizes. Therefore, incorporating microcapsules in matrix could provide good self-lubricating capability towards polymer matrix.

Traditional microcapsules were normally fabricated through interfacial polymerization, ${ }^{[15,16]}$ in situ polymerization ${ }^{[17,18]}$ or microfluid ${ }^{[19,20]}$ methods, obtaining polyurethane or PUF shells. The weak shell strength decreased the strength of the composites, resulting in the weaker resistance to abrasion. Boosting shell strength was a proper way to improve the mechanical stability of microcapsules. Increasing shell thickness, ${ }^{[10,21]}$ introducing inorganic fillers, ${ }^{[22]}$ higher crosslink density, ${ }^{[23]}$ and fabricating glass shells ${ }^{[24]}$ were published successfully to boost microcapsules strength. However, the composite strength containing such microcapsules still decreased obviously with the addition of microcapsules. Recently, a new encapsulation technique was developed by plating chemically a layer of Nickel-P alloy on the surface of microcapsules, and final microcapsules showed outstanding compressive strength and stability in organic solvents. ${ }^{[25]}$ More interestingly, the metal microcapsules remained stable compression modulus of composites. However, there was still a high demand to investigate the influence of metal shells on the tribology performance of the epoxy composite.
In this investigation, the chemical plating technique was applied to fabricate metal microcapsules for higher shell strength than polymer microcapsules. The mechanical performance of epoxy composites containing metal microcapsules and polymer microcapsules was investigated systematically. Besides, the tribology performance of epoxy composites containing metal microcapsules was tested under various conditions containing loads and sliding velocities and comparing with the results of epoxy composites containing polymer microcapsules.

\section{Experimental details}

\subsection{Materials}

Suprasec 2644 (4,4'-diphenylmethane diisocyanate) prepolymer was obtained from Huntsman. 4,4'-methylenebis (cyclohexyl isocyanate) (HMDI), gum Arabic, ethylene maleic anhydride (EMA), ammonium chloride $\left(\mathrm{NH}_{4} \mathrm{Cl}\right)$, tetraethylenepentamine (TEPA), hydrochloric acid solution $(\mathrm{HCl}, 0.1 \mathrm{M})$, sodium hydroxide $(\mathrm{NaOH})$, sodium chloride $(\mathrm{NaCl})$, palladium chloride, stannous chloride, Nickel sulfate, sodium hypophosphite monohydrate, sodium acetate, malic acid, lactic acid, thiourea, Tergitol (NP-9) and triethanolamine were obtained from Sigma-Aldrich. Epolam 5015 and hardener 5014 used as epoxy coating were supplied by Axson.

\subsection{Microencapsulation}

The metal microcapsules were fabricated through two steps. The first step was to synthesize the microcapsules with polymer shells, and the second step was to coat a layer of metal (Ni-P alloy) shell on the surface of polymer microcapsules. The synthesis process was shown in Fig. 1.

\subsubsection{Synthesis of polymer microcapsules}

The mixture of Suprasec 2644 (0.5 g) and HMDI (4.5 g) was emulsified in $30 \mathrm{ml}$ gum Arabic aqueous solutions (2.5 wt\%) under an agitation rate of 600 RPM (Fig. 1a). After stabilization $45 \mathrm{~min}, 18.0 \mathrm{~g}$ of tetraethylene pentamine (TEPA) aqueous solutions $(30 \mathrm{wt} \%)$ were introduced to start interfacial

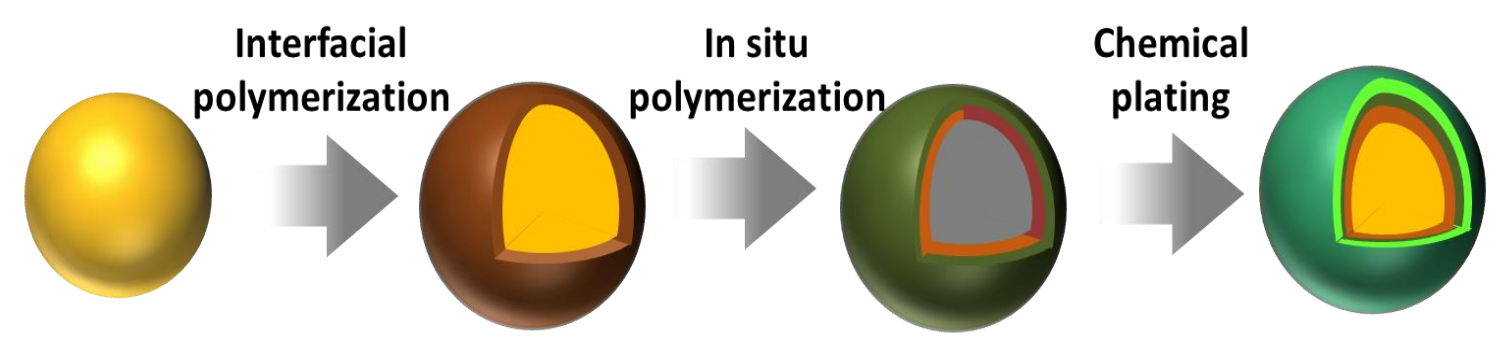
(a) Microdroplets
(b) Microcapsules
with polyurea shell
(c) Polymer microcapsules
(d) Metal microcapsules

Fig. 1 the schematic synthesis process of polymer microcapsules and metal microcapsules, (a) Microdroplets, (b) Microcapsules with polyurea shell, (c) Polymer microcapsules, and (d) Metal microcapsules. 
polymerization, and system temperature was raised to $65^{\circ} \mathrm{C}$. After reaction for $60 \mathrm{~min}$, the microcapsules slurry was washed by DI water 3-4 times (Fig. 1b) for subsequent operations.

The urea-formaldehyde prepolymer was firstly synthesized by heating the mixture solutions $(6.33 \mathrm{~g}$ formaldehyde solution (37 wt\%) and $2.5 \mathrm{~g}$ urea) at a temperature of $70{ }^{\circ} \mathrm{C}$ and $\mathrm{pH}$ values of 8.0 for $1 \mathrm{~h}$. Subsequently, the prepolymer was mixed uniformly with $1.5 \mathrm{~g}$ resorcinol, $0.75 \mathrm{~g}$ EMA and $60 \mathrm{ml}$ DI water, followed by the adjustment of $\mathrm{pH}$ values to 3.0. Then, microcapsules slurry was added into the mixture and system temperature was raised to $55^{\circ} \mathrm{C}$. After 2 hours, the final microcapsules were washed by DI water several times to obtain polymer microcapsules slurry (Fig. 1c).

\subsubsection{Synthesis of metal microcapsules}

The Pd particles were firstly prepared by reacting $0.025 \mathrm{~g}$ of $\mathrm{PdCl}_{2}$ and $0.065 \mathrm{~g}$ of $\mathrm{SnCl}_{2}$ in concentrated $\mathrm{HCl}$ solution for $10 \mathrm{~min}$. Then, polymer microcapsules slurry was introduced and the Pd particles were absorbed on the surface of microcapsules. After wash for several times, the polymer microcapsules with Pd particles on the surfaces were obtained.

$3.0 \mathrm{~g}$ of nickel sulfate was mixed with $2.0 \mathrm{ml}$ of lactic acid, 1 droplet of Tergitol, $3.0 \mathrm{~g}$ of sodium hypophosphite monohydrate, $2.0 \mathrm{~g}$ of sodium acetate, $0.4 \mathrm{~g}$ of malic acid, and 10 droplets of thiourea solutions $(0.01 \mathrm{~g}$ thiourea in $100 \mathrm{ml}$ DI water), obtaining final plating solutions. The $\mathrm{pH}$ values of plating solutions were adjusted to 5.5. Subsequently, polymer microcapsules with Pd particles were added into the plating solutions and reacted for $60 \mathrm{~min}$. Then, the metal microcapsules (Fig. 1d) with Ni-P shell were obtained.

\subsection{Sample preparation}

The metal and polymer microcapsules were dispersed in epoxy resin (Epolam 5015 and hardener 5014) at a concentration of $(10 \mathrm{wt} \%$ or $30 \mathrm{wt} \%)$ to fabricate epoxy composites. Polymer microcapsules $(10 \mathrm{wt} \%)$ were dispersed directly within formulated epoxy resin followed by degassing in a vacuum to remove trapped bubbles. When metal microcapsules were dispersed in epoxy resin, the epoxy resin was required to pre-cure for $3 \mathrm{~h}$ at room temperature followed by the addition of metal microcapsules.

Tribology sample was prepared in a PTFE cylindrical mold with diameters of $30 \mathrm{~mm}$. After curing for $24 \mathrm{~h}$ at room temperature, the tribological samples were allowed for postcure for another $24 \mathrm{~h}$ at $35{ }^{\circ} \mathrm{C}$. For comparison, samples prepared from pure epoxy resin were also fabricated.

\subsection{Characterizations}

\subsubsection{Morphologies}

$\mathrm{Au}$ was firstly coated on the surface of microcapsules and sample surfaces. Scanning electron microscopy (JEOL-JSM$5600 \mathrm{LV}$ ) was applied to observe the morphologies of microcapsules and tribological samples.

The surface profilometry of tribological samples was measured through Telyscan 150 with a diamond stylus of $4 \mu \mathrm{m}$ and a scan size of $2 \mathrm{~mm} \times 2 \mathrm{~mm}$.

\subsubsection{Core fraction determination}

The core fractions of metal microcapsules were obtained from the titration method. The microcapsules were crushed through glass slides, and the NCO contents in the crushed microcapsules could be obtained through ASTM D2572-97, and then the NCO contents could be converted into the weight of HMDI based on the following equations:

$$
\begin{gathered}
m_{H M D I}=262.35 \times 0.5 \times n_{N C O}= \\
131.18 \times \frac{\left(V_{\text {blank }}-V\right) \times c_{H C l}}{2000} \\
\text { core fraction }(\mathrm{wt} \%)=\frac{\frac{m_{H M D I}}{m_{\text {microcpasules }}} \times 100 \%}{}
\end{gathered}
$$

\subsubsection{Mechanical properties}

The mechanical properties of epoxy composites containing microcapsules were tested through compression strength and compression modulus, both of which were tested based on ASTM-D695 through Instron machine (Instron 5500R) with a loading speed of $1 \mathrm{~mm} / \mathrm{min}$.

\subsection{The test of tribology performances}

Samples including pure epoxy, composites containing $10 \mathrm{wt} \%$ of polymer microcapsules (Composite's polymer microcapsules-10 wt $\%$ ), composites containing $10 \mathrm{wt} \%$ of metal microcapsules (Composite's metal microcapsules-10 $\mathrm{wt} \%$ ), and composites containing $30 \mathrm{wt} \%$ of metal microcapsules (Composite's metal microcapsules-30 wt\%) were conducted through a tribological tests.

The surfaces of samples were polished with a 1500 mesh sandpaper and the surface was flushed by DI water and ethanol to remove residual debris. Tribology test was conducted based on a ball-on-disk method by rolling Cr6 steel balls with a diameter of $6 \mathrm{~mm}$ (micro tribometer CSM). The radius of circular wear was $3 \mathrm{~mm}$. The tribological test was conducted by sliding against a $\mathrm{Cr} 6$ steel ball in diameter of $4 \mathrm{~mm}$ for $8 \mathrm{~h}$ at various sliding rates (25 REV, $50 \mathrm{REV}$, and $100 \mathrm{REV})$ under different normal loads $(3 \mathrm{~N}, 5 \mathrm{~N}$, and $10 \mathrm{~N})$. The final tribological properties of samples were characterized in terms of friction coefficient and wear loss.

\section{Results and discussion}

\subsection{Morphology of microcapsules}

Fig. 2a showed the morphologies of metal microcapsules with diameter of $200.7 \pm 44.5 \mu \mathrm{m}$, and Fig. $2 \mathrm{~b}$ demonstrated the hollow inner structures of metal microcapsules with a shell thickness of $5.2 \pm 1.4 \mu \mathrm{m}$. Fig. 2c showed the well-dispersed polymer microcapsules with a diameter of $185.2 \pm 44.2 \mu \mathrm{m}$, and Fig. 2d also demonstrated the obvious core-shell structures and shell thickness of $2.7 \pm 0.6 \mu \mathrm{m}$. Metal microcapsules had similar diameter with polymer microcapsules. The surface of metal microcapsules had some bumps, but polymer microcapsules were smooth due to different deposition mechanisms. Moreover, the shell thickness of metal 


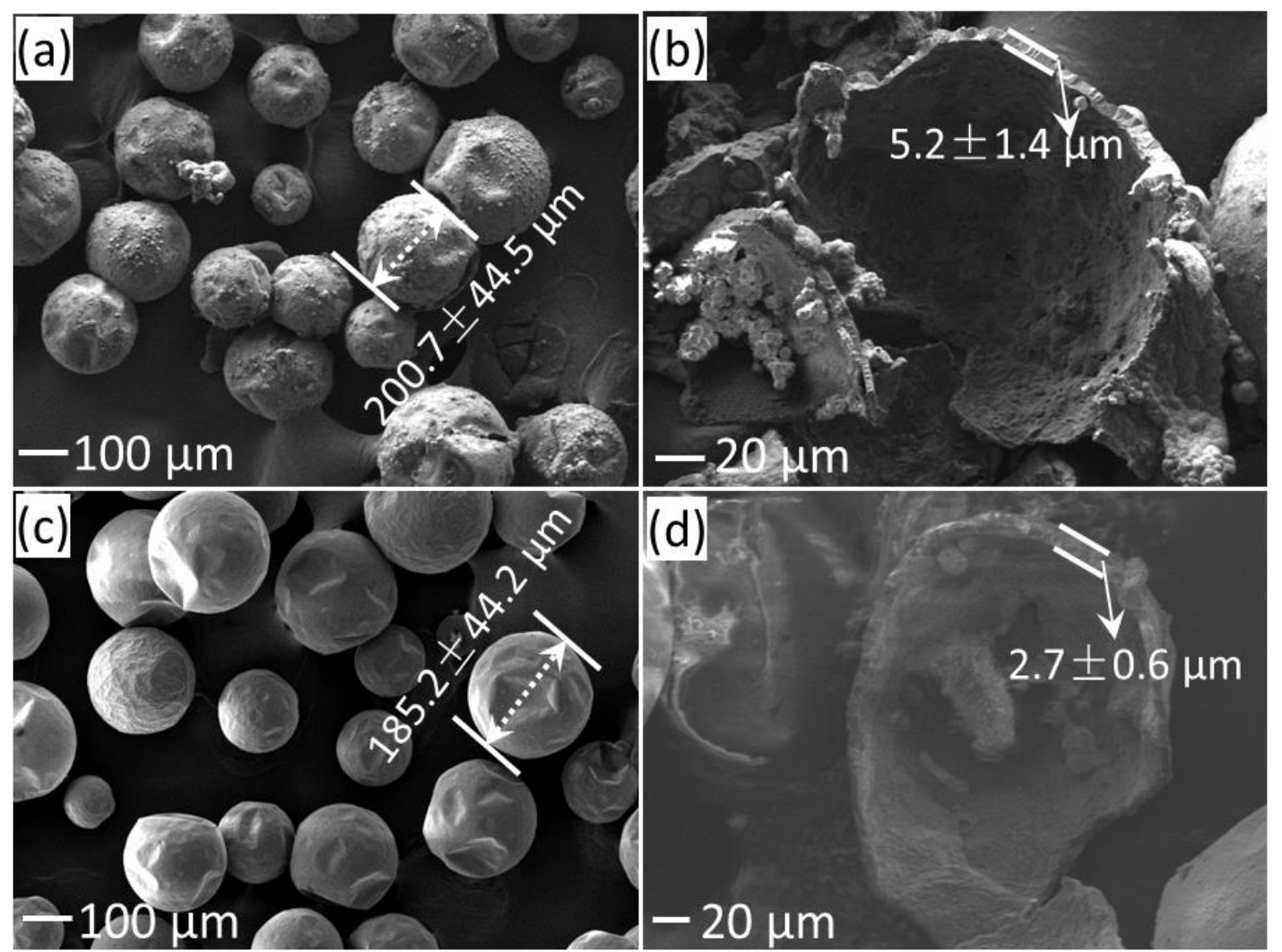

Fig. 2 The morphologies of metal microcapsules and polymer microcapsules, (a) well-dispersed metal microcapsules; (b) broken metal microcapsules with obvious core-shell structures; (c) well-dispersed polymer microcapsules; and (d) broken polymer microcapsules with clear core-shell structures.

microcapsules was larger than that of polymer microcapsules due to the existence of a metal shell with a thickness of around $2.5 \mu \mathrm{m}$. Besides, the core fraction of metal microcapsules and polymer microcapsules was $23.5 \pm 1.3 \mathrm{wt} \%$ and $75.0 \pm 2.1 \mathrm{wt} \%$, respectively. The lower core fraction of metal microcapsules was due to the high density of Ni-P alloy $\left(8.9 \mathrm{~g} / \mathrm{cm}^{3}\right)$.
EDX spectra was used to characterize the composition of Nickel-P alloy, as shown in Fig. 3. The rectangular region was chosen as the test region (Fig. 3a). From Fig. 3b and Fig. 3c, it was observed that the Nickel elements and Phosphorous accounted for $88.1 \mathrm{w} \%$ and $11.9 \mathrm{w} \%$ of metal shells, respectively.
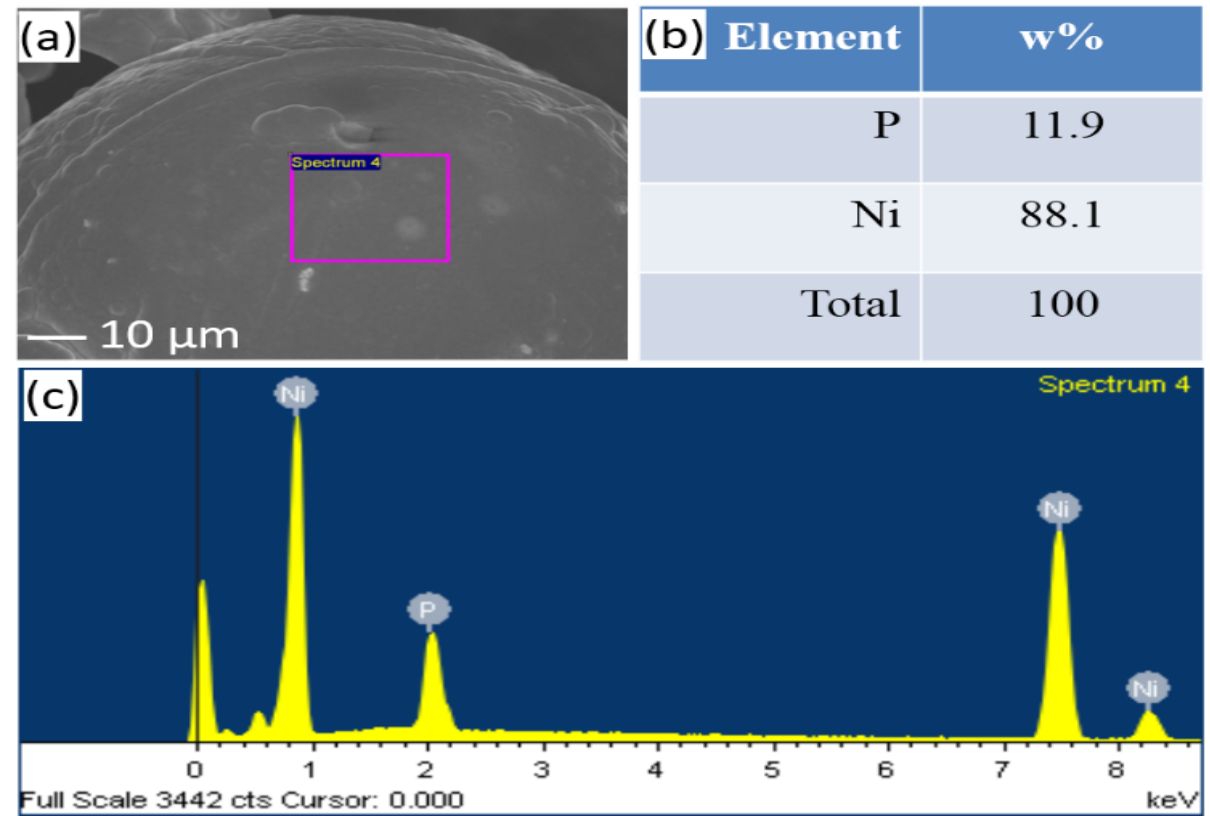

Fig. 3 (a) The test region on the surface of metal microcapsules; (b) The percentage of different elements, and (c) EDX spectra of the test region. 
(a)

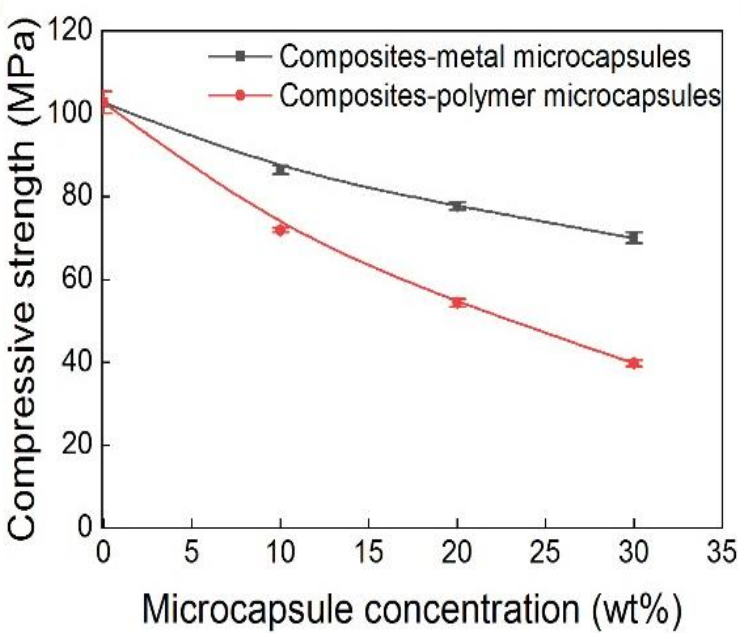

Fig. 4 Compressive strength (a) and compressive modulus microcapsules as a function of microcapsule concentration.

\subsection{Mechanical properties of epoxy composites}

Although both metal microcapsules and polymer microcapsules had similar diameters, the representative composites showed different mechanical properties. As shown in Fig. 4a, the compressive strength of composites containing metal microcapsules were decreased from 102.6 $\pm 2.6 \mathrm{MPa}$ to 86.4 $\pm 0.9 \mathrm{MPa}, 77.6 \pm 0.9 \mathrm{MPa}$, and $70.0 \pm 1.2 \mathrm{MPa}$, and the compressive strength of composites containing polymer microcapsules was decreased from $102.6 \pm 2.6 \mathrm{MPa}$ to $71.9 \pm 0.5 \mathrm{MPa}, 54.3 \pm 1.0 \mathrm{MPa}$, and $39.7 \pm 0.8 \mathrm{MPa}$, when microcapsules concentrations were increased from $0 \mathrm{wt} \%$ to $10 \mathrm{wt} \%, 20 \mathrm{wt} \%$, and $30 \mathrm{wt} \%$. The compressive strength of both epoxy composites was decreased with the increase of microcapsules concentrations, because microcapsules were considered as a kind of flaws in epoxy composites and more flaws brought compressive strength of epoxy composites. However, the epoxy composites containing metal microcapsules had higher compressive strength than epoxy composites containing polymer microcapsules because of the higher strength of metal shells.

Although the compressive strength of both epoxy composites was decreased obviously with the increase of microcapsules concentrations. However, their compressive modulus showed different behaviors. As shown in Fig. 4b, the compressive modulus of composites containing metal microcapsules was decreased from $2.61 \pm 0.1 \mathrm{GPa}$ to $2.52 \pm 0.02$ $\mathrm{GPa}, 0.53 \pm 0.01 \mathrm{GPa}$, and $2.36 \pm 0.01 \mathrm{GPa}$, and the compressive modulus of composites containing polymer microcapsules was decreased from $2.61 \pm 0.1 \mathrm{GPa}$ to $2.2 \pm 0.07 \mathrm{GPa}, 1.74 \pm 0.05$ $\mathrm{GPa}$, and $1.09 \pm 0.06 \mathrm{GPa}$, when microcapsules concentrations were increased from $0 \mathrm{wt} \%$ to $10 \mathrm{wt} \%, 20 \mathrm{wt} \%$, and $30 \mathrm{wt} \%$. The compressive modulus of composites containing metal microcapsules remained stable relatively, but that of epoxy composites containing polymer microcapsules was decreased obviously with the increase of microcapsule concentrations. (b)

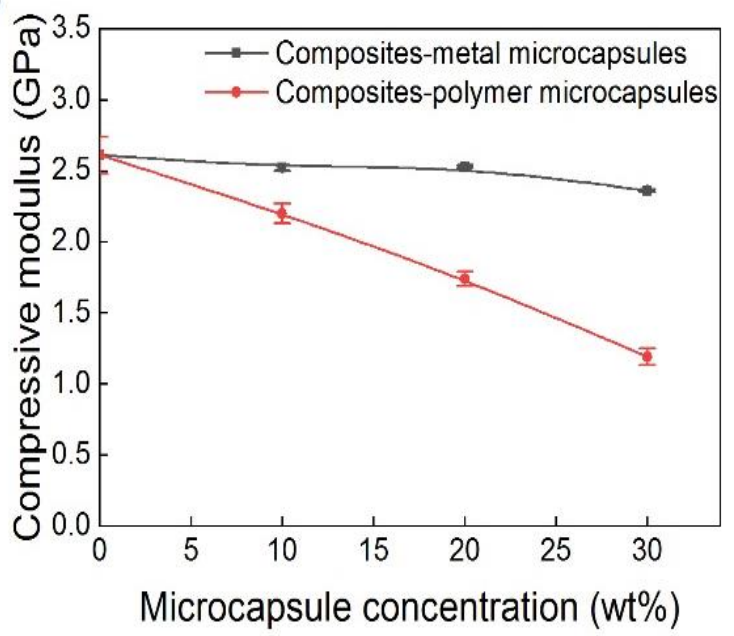

(b) of composites containing metal microcapsules and polymer The main reason was that metal shells had a similar modulus with cure epoxy resin, ${ }^{[25]}$ but the modulus of polymer microcapsules was far lower than pure epoxy resin.

\subsection{The influence of normal loads on tribology of epoxy composites}

Three normal loads $(3 \mathrm{~N}, 5 \mathrm{~N}$, and $10 \mathrm{~N})$ were applied to tribological experiments of pure epoxy samples, composites metal microcapsules-10 wt $\%$, composites metal microcapsules-30 wt $\%$, and composites polymer microcapsules- $10 \mathrm{wt} \%$ at the sliding rate of $50 \mathrm{REV}$, and wear duration was set as $8 \mathrm{hrs}$. The average value between $10000 \mathrm{~s}$ and $28800 \mathrm{~s}$ was set as the friction coefficient of samples.

\subsubsection{Influence of normal loads on the friction process}

Fig. 5 presented the friction coefficients of pure epoxy samples (a), composites metal microcapsules-10 wt \% (b), composites metal microcapsules-30 wt $\%$ (c), and composites polymer microcapsules-10wt $\%$ (d) as a function of friction durations. The friction coefficients of all samples were increased firstly until balance with durations under various normal loads. At the beginning of the friction process, the smooth surface of the steel ball was roughened gradually by friction process resulting in a gradual increase of friction coefficient until balance. Normally, the steel ball was roughened more easily under higher normal loads, and therein faster velocity to reach a balance. Moreover, the metal shells were polished into powder covering on the wear track, resulting in rougher surfaces and therein higher friction coefficients. Although the metal microcapsules could release liquid isocyanate, the liquid agents was absorbed gradually by the compact tribolayer and lost lubricating functions. For polymer microcapsules- $10 \mathrm{wt} \%$ samples, the polymer microcapsules could release massive liquid core as lubricant on the wear track, resulting in the instant balance of friction coefficient within several loops. 

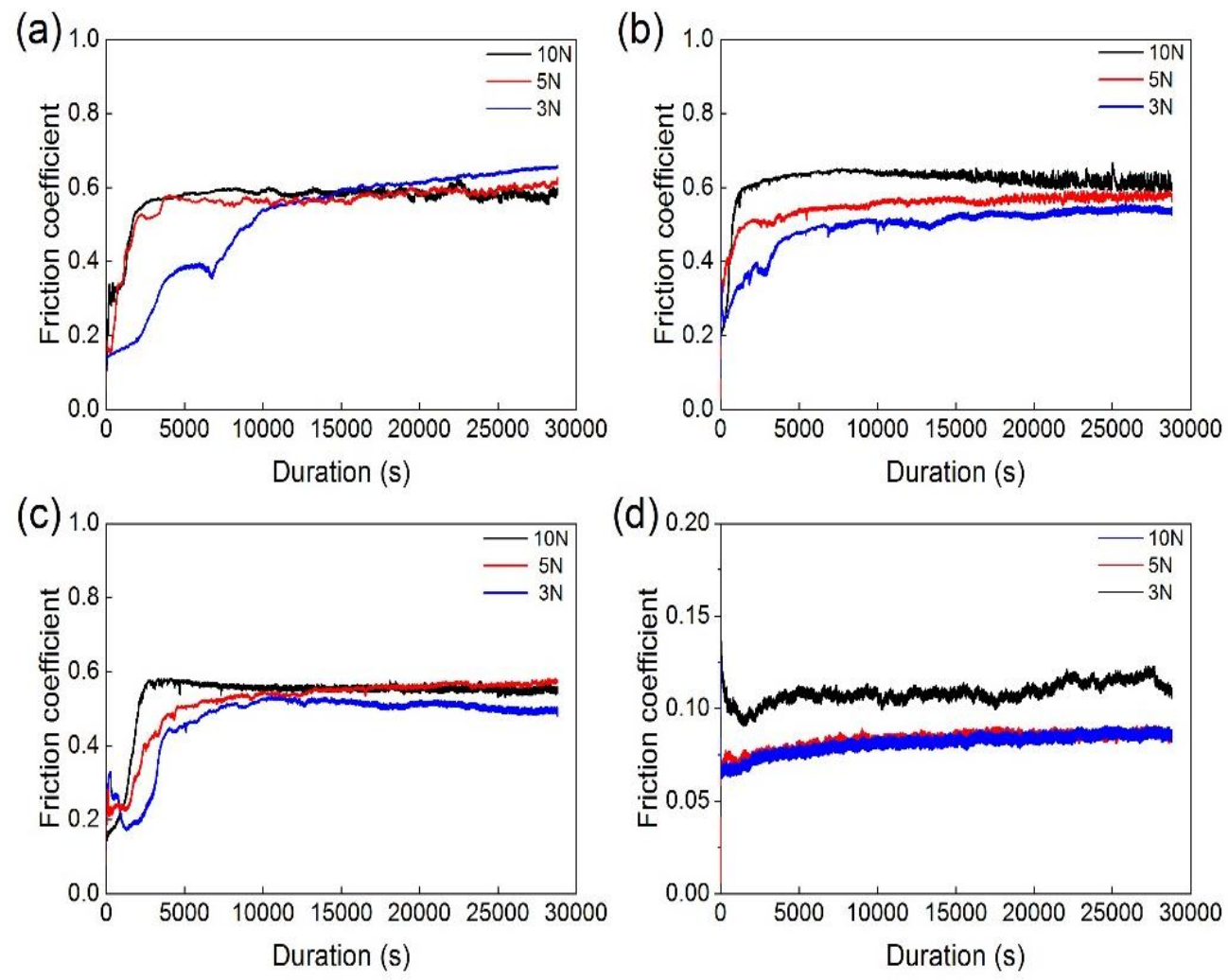

Fig. 5 Friction coefficient of samples as a function of durations under different normal load ( $3 \mathrm{~N}, 5 \mathrm{~N}$, and $10 \mathrm{~N})$ at a sliding velocity of 50 REV. (a) Pure epoxy samples; (b) Composites metal microcapsules-10 wt\%; (c) Composites metal microcapsules-30 wt $\%$, and (d) composites polymer microcapsules-10 $\mathrm{wt} \%$.

However, the friction coefficient of polymer microcapsules-10 $\mathrm{wt} \%$ samples was still increased slightly over friction durations due to the increase of contact interface, which tended to increase the mechanical interlocking between two mating surfaces. ${ }^{[26,27]}$

Besides, the tribolayer of pure epoxy samples, composites metal microcapsules-10 wt $\%$, composites metal microcapsules-30 wt $\%$ were observed obviously on the wear track, as shown in Fig. $6\left(a_{1}, b_{1}, c_{1}\right)(3 N),\left(a_{2}, b_{2}, c_{2}\right)(5 N)$ and $\left(a_{3}, b_{3}, c_{3}\right)(10 N)$. However, the same tribolayer was not observed on the wear track of composites polymer microcapsules-10 $\mathrm{wt} \%$ samples due to the existence of massive liquid lubricant, as shown in Fig. $6, d_{1}(3 N), d_{2}(5 N)$, and $\mathrm{d}_{3}(10 \mathrm{~N})$. When massive liquid HMDI was released onto the wear track of composites polymer microcapsules- $10 \mathrm{wt} \%$, the wear of the matrix was retarded and less debris was produced. The tribolayer was mainly made from the wear debris compacting on the wear track. Therefore, it was reasonable to observe the disappearance of tribolayer on wear track of composites containing polymer microcapsules.

\subsubsection{Influence of normal loads on the friction coefficient of composites}

The friction coefficient of pure epoxy samples, composites polymer microcapsules-10 wt $\%$ samples, composites metal microcapsules-10 $\mathrm{wt} \%$ samples, and composites metal microcapsules-30 wt\% samples showed different trends under increasing normal loads, as shown in Fig. 7. When normal loads were increased from $3 \mathrm{~N}$ to $5 \mathrm{~N}$ and $10 \mathrm{~N}$, the friction coefficient of pure epoxy samples decreased slightly from 0.6085 to 0.5819 and 0.5837 , the friction coefficients of composites metal microcapsules-10 wt $\%$ samples were increased from 0.525 to 0.569 and 0.623 , the friction coefficient of metal microcapsules- $30 \mathrm{wt} \%$ samples fluctuated slightly from 0.5104 to 0.5569 and 0.5525 , and the friction coefficient of composites polymer microcapsules-10 $\mathrm{wt} \%$ decreased from 0.1105 to 0.0856 and 0.08418 .

The friction coefficient of pure epoxy samples was decreased slightly under higher normal loads. Under higher normal loads, the tribolayer on the wear track of pure epoxy samples were more compact, resulting in smaller friction coefficients by minimizing the contact between two rubbing surfaces. In comparison, the friction coefficient of composites metal microcapsules-10 wt\% samples was increased under higher normal loads. Although more liquid core was released into wear track to decrease the friction coefficient under higher normal loads, more metal shell was also polished into powder to absorb more liquid lubricant, resulting in higher friction coefficients. ${ }^{[4]}$ The friction coefficients of composites metal microcapsules-30 wt $\%$ samples were increased firstly followed by a decrease under higher normal loads. When the normal load was increased from $3 \mathrm{~N}$ to $5 \mathrm{~N}$, more metal powder was produced to absorb more liquid core increasing the friction coefficient. When normal load increased from $5 \mathrm{~N}$ 

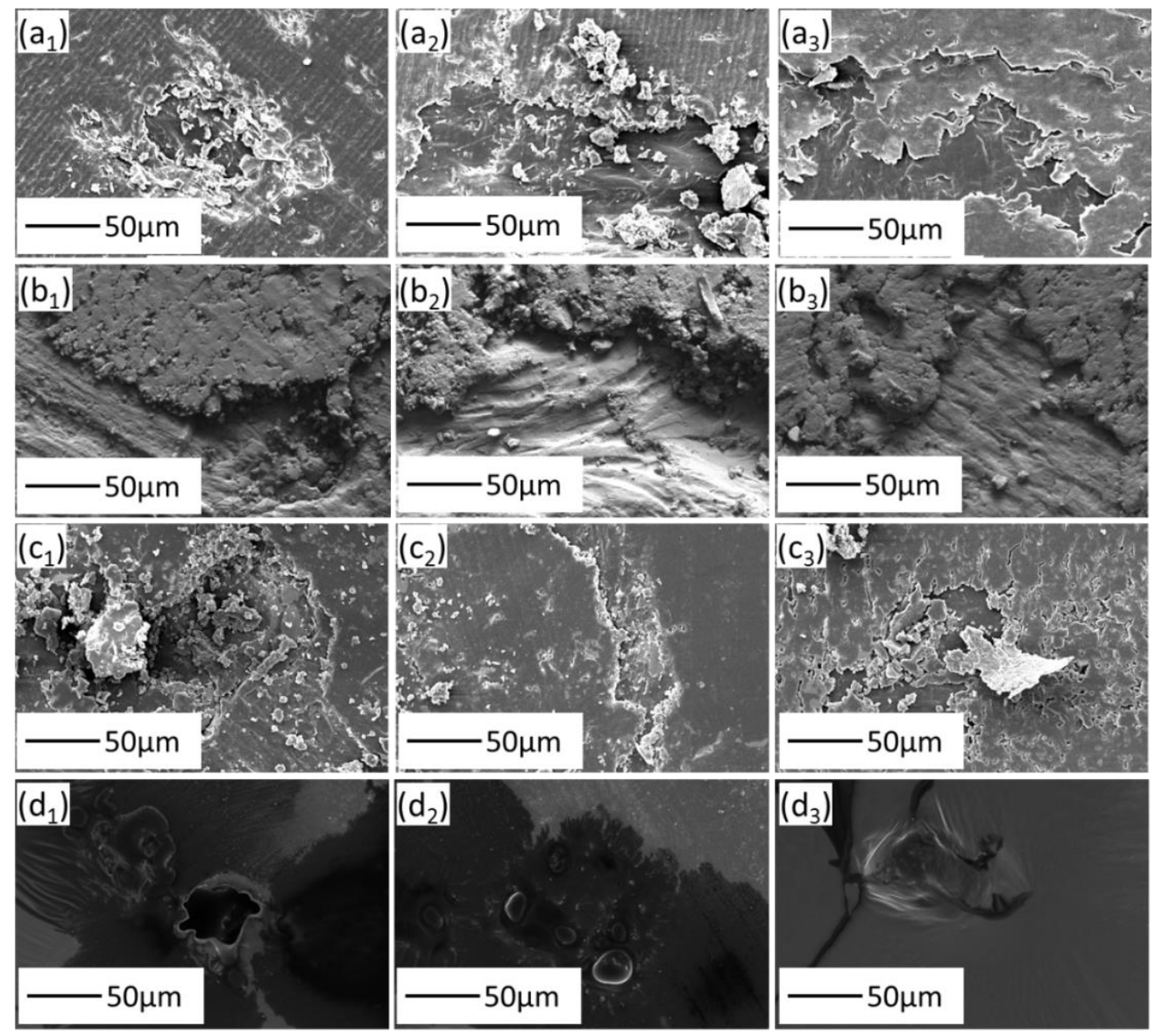

Fig. 6 The detailed morphology of the wear track of pure epoxy samples (a), composites metal microcapsules-10 wt $\%$ (b), composites metal microcapsules-30 wt\% (c), and composites polymer microcapsules-10 wt \% (d) under normal loads of $3 \mathrm{~N}\left(\mathrm{a}_{1}, \mathrm{~b}_{1}, \mathrm{c}_{1}, \mathrm{and}_{\mathrm{l}}\right.$ ), $5 \mathrm{~N}\left(\mathrm{a}_{2}, \mathrm{~b}_{2}, \mathrm{c}_{2}\right.$, and $\left.\mathrm{d}_{2}\right)$ and $10 \mathrm{~N}\left(\mathrm{a}_{3}, \mathrm{~b}_{3}, \mathrm{c}_{3}\right.$, and $\left.\mathrm{d}_{3}\right)$.

to $10 \mathrm{~N}$, although more wear also occurred to increase friction coefficient, more microcapsules were also broken to release more liquid HMDI as a lubricant for friction mitigation. Moreover, the formed tribolayer on the track was more compact under higher normal loads, decreasing the friction coefficient. However, the friction coefficients of composites polymer microcapsules-10 wt $\%$ samples were decreased slightly under higher normal loads. Under higher normal loads, more microcapsules were broken and more HMDI was released to serve as a lubricant to decrease the friction coefficients. Moreover, no metal shells were polished into powder to retard the lubricating performance of HMDI, resulting in the gradual decrease of friction coefficient in composites containing polymer microcapsules.

The metal shell of microcapsules influenced significantly the friction coefficient of composites. When polymer microcapsules were embedded in composites, the microcapsules were easily broken and released liquid HMDI core as a lubricant to decrease friction coefficient. Comparing with pure epoxy samples, the friction coefficient of composites polymer microcapsules- 10 wt $\%$ samples decreased by $81.8 \%(3 \mathrm{~N}), 85.3 \%(5 \mathrm{~N})$, and $85.6 \%(10 \mathrm{~N})$ under different normal loads, respectively. In comparison, the friction coefficient of composite metal microcapsules- $10 \mathrm{wt} \%$

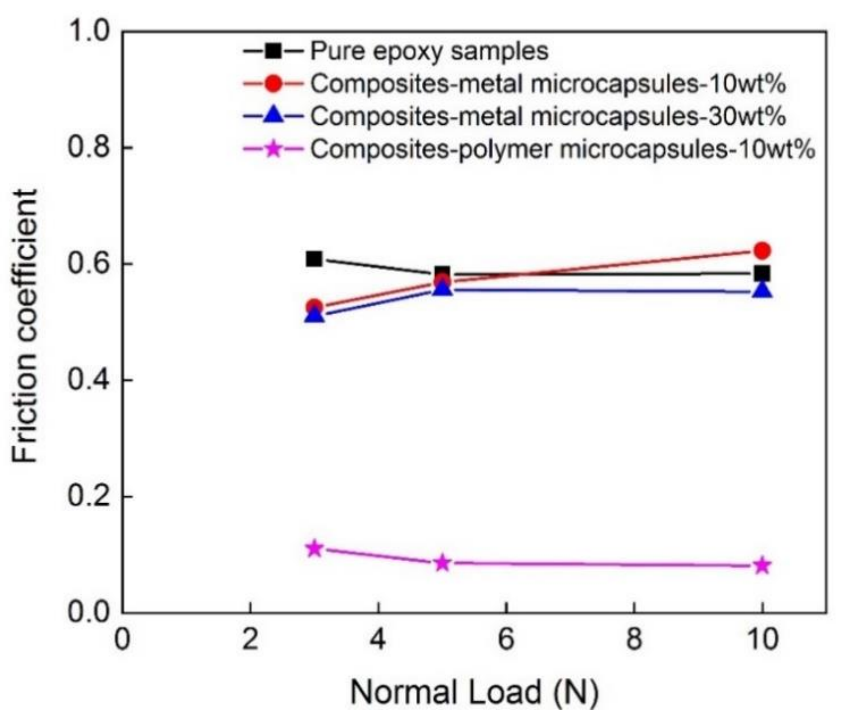

Fig. 7 The friction coefficient of pure epoxy samples, composites metal microcapsules-10 wt $\%$, composites metal microcapsules$30 \mathrm{wt} \%$, and composites polymer microcapsules-10 wt $\%$ as a function of normal load $(3 \mathrm{~N}, 5 \mathrm{~N}$, and $10 \mathrm{~N})$.

decreased by $13.3 \%, 3.4 \%$, and $-6.7 \%$ compared with pure epoxy samples under normal loads of $3 \mathrm{~N}, 5 \mathrm{~N}$, and $10 \mathrm{~N}$, respectively. The main reason was that the metal shell powder 


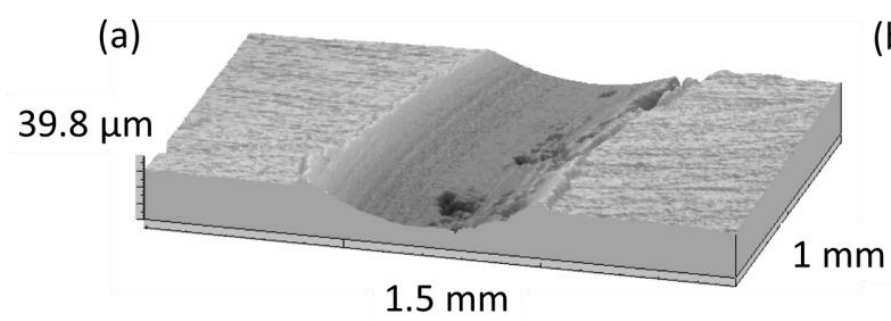

(b)

Fig. 8 (a) The topography of wear track of pure epoxy samples (5N, 50 REV); (b) Profile of related wear track.

tended to increase adhesion wear and absorb liquid cores by forming compact layer. Even when the concentration of embedded metal microcapsules increased from $10 \mathrm{wt} \%$ to 30 $\mathrm{wt} \%$, the friction coefficient of composites was improved very slightly. Therefore, it was reasonable to conclude that the metal shell influenced negatively on the lubricant performance of epoxy composites.

\subsubsection{Influence of normal loads on wear loss of composites} Besides friction efficiency, normal loads also affected significantly the wear loss of epoxy composites including pure epoxy samples, composites polymer microcapsules- $10 \mathrm{wt} \%$, composites metal microcapsules- $10 \mathrm{wt} \%$, and composites metal microcapsules-30 wt $\%$, and the wear loss was characterized in terms of wear width and wear depth, as shown in Fig. 8a and Fig. 8b. The wear width and wear depth were obtained from the surface topographies of the wear track, and typical topographies (a) and profile (b) of the wear track (pure epoxy samples, 5 N, 50 REV) were shown in Fig. 8.

Fig. 9a showed that wear width varied as a function of normal loads under a sliding velocity of $50 \mathrm{REV}$. When normal loads were increased from $3 \mathrm{~N}$ to $5 \mathrm{~N}$ and $10 \mathrm{~N}$, the wear width of samples was increased from $0.62 \pm 0.05 \mathrm{~mm}$ (pure epoxy samples) to $1 \pm 0.06 \mathrm{~mm}$ and $1.57 \pm 0.12 \mathrm{~mm}$; from $0.68 \pm 0.05$ $\mathrm{mm}$ (composites metal microcapsules- $10 \mathrm{wt} \%$ ) to $0.94 \pm 0.04$ $\mathrm{mm}$ and $2 \pm 0.07 \mathrm{~mm}$; from $0.64 \pm 0.03 \mathrm{~mm}$ (composites metal microcapsules- $30 \mathrm{wt} \%$ ) to $0.9 \pm 0.05 \mathrm{~mm}$ and $1.47 \pm 0.18 \mathrm{~mm}$; from $0.4 \pm 0.06 \mathrm{~mm}$ (composites polymer microcapsules- 10

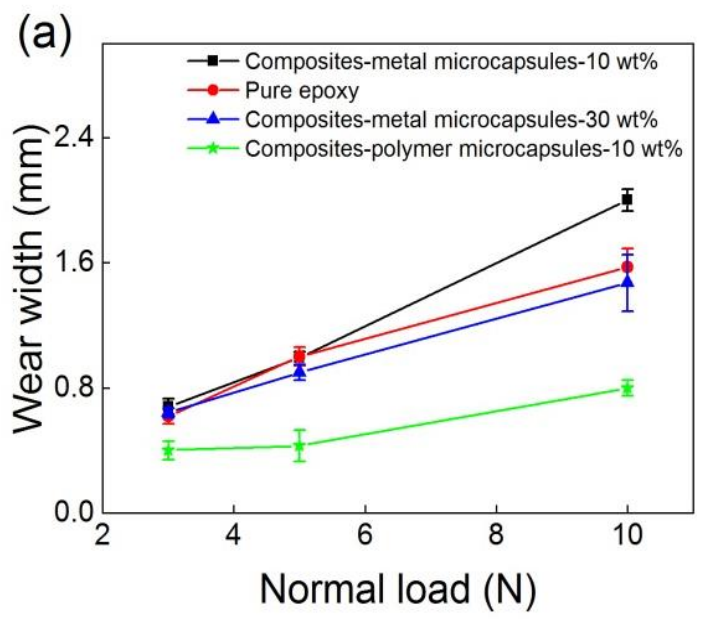

wt $\%), 0.43 \pm 0.1 \mathrm{~mm}$ and $0.8 \pm 0.05 \mathrm{~mm}$, respectively. Fig. $9 \mathrm{~b}$ presented that the wear depth of samples also was increased obviously under higher normal loads. When normal loads increased from $3 \mathrm{~N}$ to $5 \mathrm{~N}$ and $10 \mathrm{~N}$, the wear depth of samples was increased from $17.84 \pm 2.44 \mu \mathrm{m}$ (pure epoxy samples) to $58.2 \pm 4.22 \mu \mathrm{m}$ and $180.55 \pm 27.54 \mu \mathrm{m}$; from $20.5 \pm 2.77 \mu \mathrm{m}$ (composites metal microcapsules-10 $\mathrm{wt} \%$ ) to $58.56 \pm 9.94 \mu \mathrm{m}$ and $236.2 \pm 16.82 \mu \mathrm{m}$; from $4.02 \pm 0.54 \mu \mathrm{m}$ (composites metal microcapsules-30 $\mathrm{wt} \%$ ) to $50.55 \pm 9.7 \mu \mathrm{m}$ and $159.87 \pm 34.95$ $\mu \mathrm{m}$; and from $1.09 \pm 0.41 \mu \mathrm{m}$ (composites polymer microcapsules-10 $\mathrm{wt} \%)$ to $5.8 \pm 3.03 \mu \mathrm{m}$ and $26.6 \pm 3.48 \mu \mathrm{m}$, respectively. The wear width of all samples was increased under higher normal loads. The main reason was that higher friction aggravated the wear of the matrix. Besides, the wear loss of composites metal shell- $10 \mathrm{wt} \%$ including wear width and wear depth was higher than that of pure epoxy samples. The main reason was that the metal microcapsules decreased the strength of the epoxy matrix and therein more wear loss. Although metal microcapsules could release liquid lubricant to mitigate wear, the liquid agents was easily absorbed by the compact layer of metal powder. Moreover, the concentration of metal microcapsules influenced slightly the wear loss of composites. When the concentration of metal microcapsules was increased from $10 \mathrm{wt} \%$ to $30 \mathrm{wt} \%$, the wear loss was improved slightly. In comparison, the wear loss of composites polymer microcapsules- $10 \mathrm{wt} \%$ was improved very obviously under various normal loads. Comparing with pure epoxy samples, the wear width of composites polymer

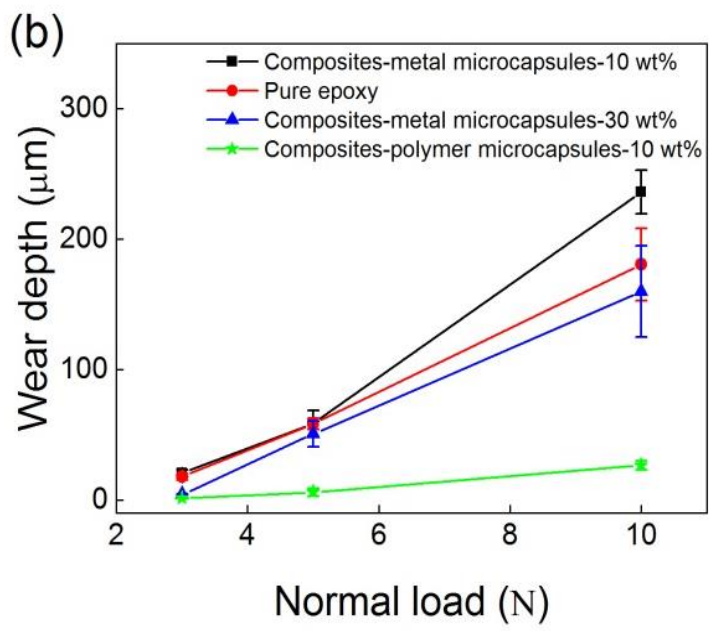

Fig. 9 The wear width (a) and wear depth (b) of pure epoxy samples, composites metal microcapsules- $10 \mathrm{wt} \%$, composites metal microcapsules- $30 \mathrm{wt} \%$, and composites polymer microcapsules- $10 \mathrm{wt} \%$ as a function of normal load $(3 \mathrm{~N}, 5 \mathrm{~N}$, and $10 \mathrm{~N})$. 
(a)

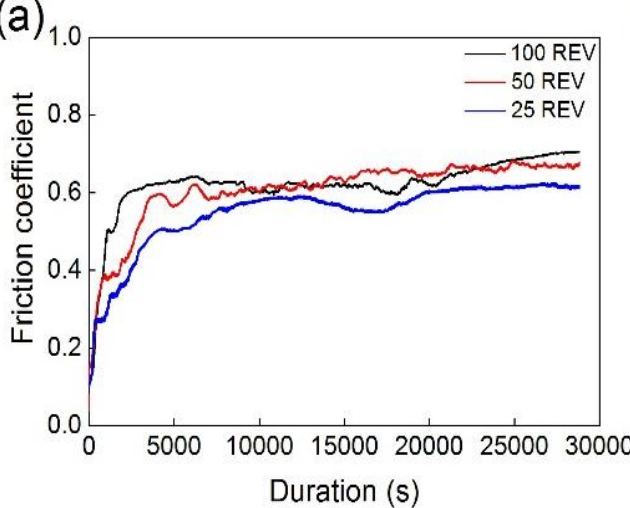

(c)

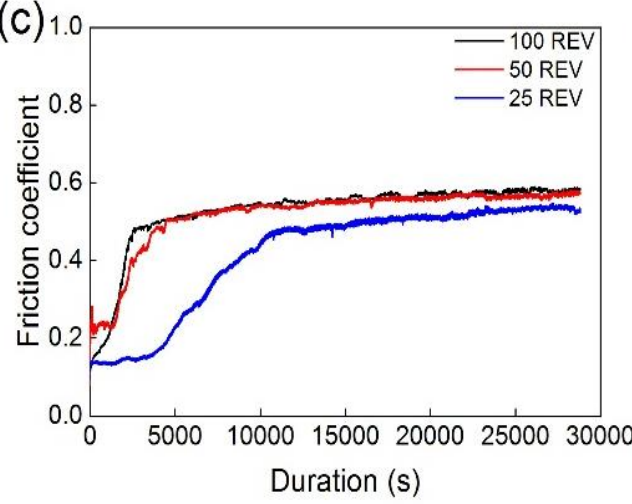

(b)

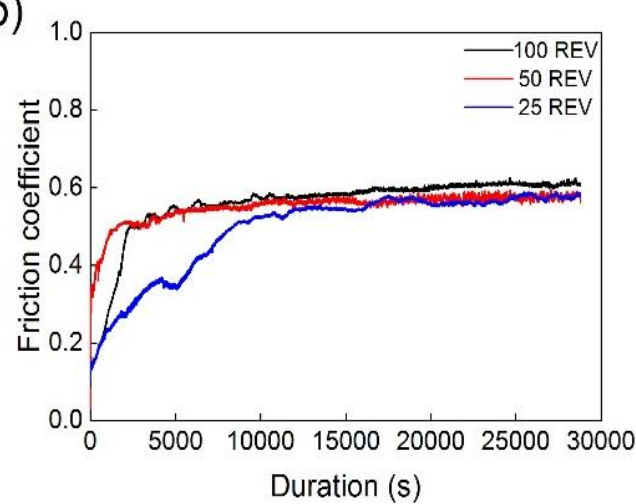

(d)

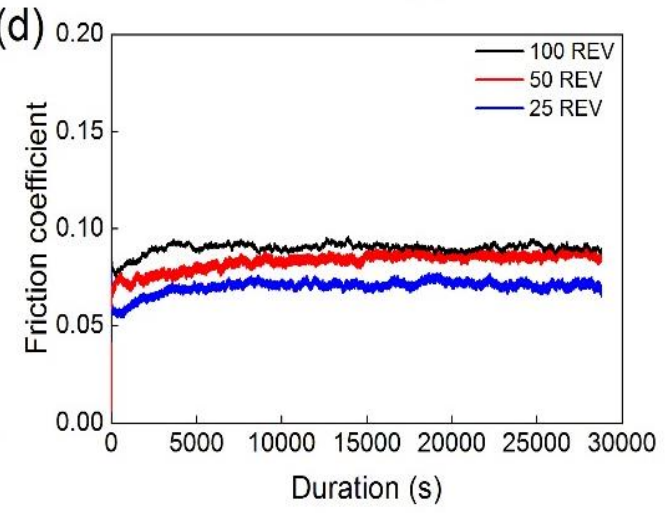

Fig. 10 Friction coefficient of pure epoxy samples (a), composites metal microcapsules- $10 \mathrm{wt} \%$ (b), composites metal microcapsules$30 \mathrm{wt} \%$ (c), and composites polymer microcapsules $10 \mathrm{wt} \%$ (d) as a function of duration under normal load of $5 \mathrm{~N}$ at sliding rates of $25 \mathrm{REV}, 50 \mathrm{REV}$ and $100 \mathrm{REV}$.

3.4 The influence of sliding velocities on the tribology of epoxy composites

Besides normal loads, sliding velocities also influenced significantly the friction coefficient and wear loss of epoxy composites. Increasing sliding velocities of $25 \mathrm{REV}, 50 \mathrm{REV}$, and $100 \mathrm{REV}$ were applied to tribological experiments of samples for $8 \mathrm{hrs}$ under a normal load of $5 \mathrm{~N}$. The tribological performances of samples were characterized in terms of friction coefficient and wear loss.

\subsubsection{Influence of sliding velocities on the friction process of composites}

Fig. 10 showed the friction coefficient of pure epoxy samples (a), composites metal microcapsules- $10 \mathrm{wt} \%$ (b), composites metal microcapsules-30 wt\% (c), and composites polymer microcapsules- $10 \mathrm{wt} \%$ (d) as a function of friction durations under a normal load of $5 \mathrm{~N}$ at different sliding velocities ( 25 REV, $50 \mathrm{REV}$, and $100 \mathrm{REV}$ ). The friction coefficients of all samples reached balance faster under higher sliding velocities because the steel balls were roughened faster under higher sliding velocities. For composites polymer microcapsules-10 wt $\%$ samples, the friction coefficient arrived instantly at the balance at the beginning of the friction test. The main reason was that the polymer microcapsules were weak enough to be easily broken and released a massive liquid core as a lubricant at the beginning of the friction process. The lubricants kept the friction coefficient of composites polymer microcapsules- 10 $\mathrm{wt} \%$ at a low value. After balance, the friction coefficients of all samples increased slightly over durations due to a slight increase of contact interface resulting in the aggravation of mechanical interlock. In addition, the wear track was deeper and wider with the friction process and therein larger contact interfaces. A larger contact surface was usually accompanied by more mechanical interlock and an increase of friction coefficient.

The formed tribolayer of pure epoxy samples (a), composites metal microcapsules- $10 \mathrm{wt} \%$ (b), and composites metal microcapsules- $30 \mathrm{wt} \%$ on the track at sliding velocities of $25 \operatorname{REV}\left(\mathrm{a}_{1}, \mathrm{~b}_{1}, \mathrm{c}_{1}\right), 50 \operatorname{REV}\left(\mathrm{a}_{2}, \mathrm{~b}_{2}, \mathrm{c}_{2}\right)$ and $100 \mathrm{REV}$ $\left(a_{3}, b_{3}, c_{3}\right)$ were observed in Fig. 11. However, the tribolayer was not formed on the wear track of composites polymer microcapsules-10 wt $\%$, as shown in Fig. $11\left(d_{1}, d_{2}\right.$, and $\left.d_{3}\right)$, because a massive liquid core was released as a lubricant to retard the formation of tribolayer.

\subsubsection{Influence of sliding velocities on the friction coefficient of composites}

Samples containing pure epoxy samples, composites metal microcapsules- $10 \mathrm{wt} \%$, composites metal microcapsules-30 $\mathrm{wt} \%$, and composites polymer microcapsules $-10 \mathrm{wt} \%$ were applied to the tribological test under normal loads of $5 \mathrm{~N}$ for 8 hrs at increasing sliding velocities (25 REV, $50 \mathrm{REV}$, and 100 REV). The average value of the friction coefficient from 10000 s to the end was set as the friction coefficient of samples. 

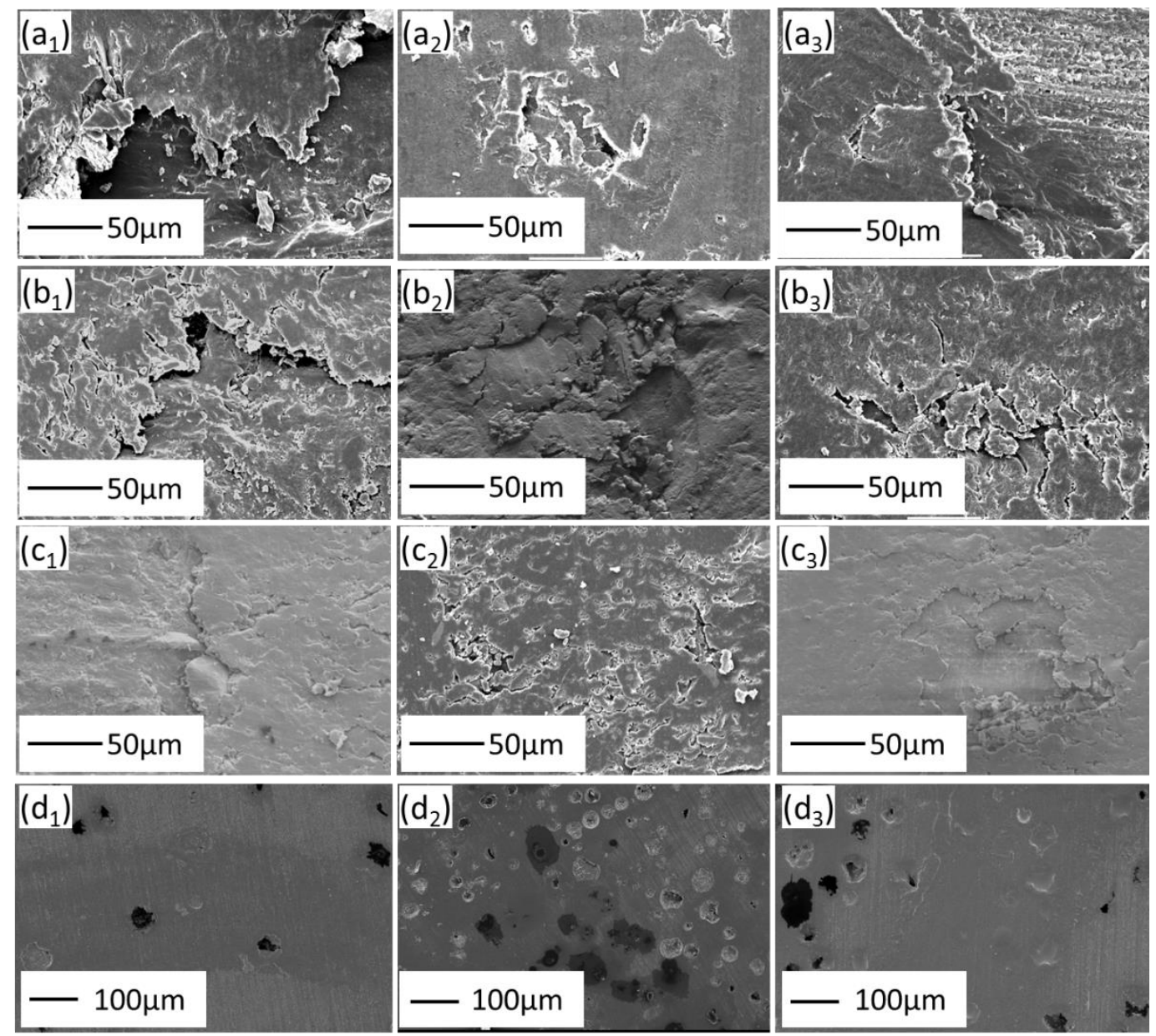

Fig. 11 The detailed morphology of the wear track of pure epoxy samples (a), composites metal microcapsules-10 wt\% (b), composites metal microcapsules-30 wt \% (c) and composites polymer microcapsules-10 wt\% (d) at sliding rate of $25 \mathrm{REV}\left(\mathrm{a}_{1}, \mathrm{~b}_{1}, \mathrm{c}_{1}\right.$ and $\left.d_{1}\right), 50 \operatorname{REV}\left(a_{2}, b_{2}, c_{2}\right.$ and $\left.d_{2}\right)$ and $100 \operatorname{REV}\left(a_{3}, b_{3}, c_{3}\right.$ and $\left.d_{3}\right)$.

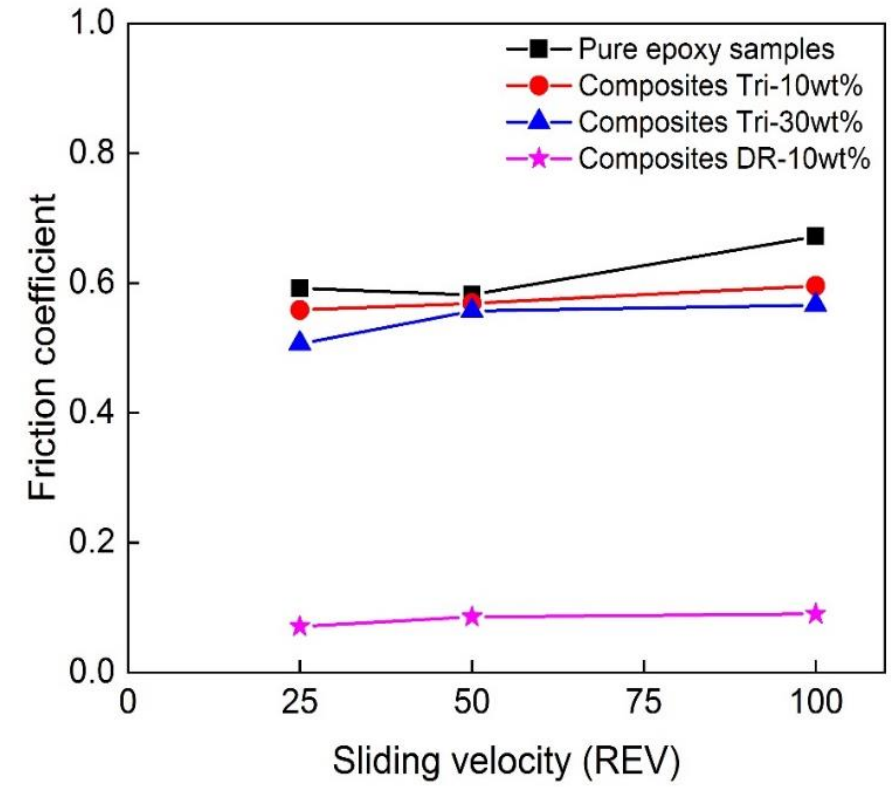

Fig. 12 The friction coefficient of pure epoxy samples, composites metal microcapsules-10 $\mathrm{wt} \%$, composites metal microcapsules-30 wt $\%$, and composites polymer microcapsules$10 \mathrm{wt} \%$ as a function of sliding velocity (25 REV, $50 \mathrm{REV}$, and $100 \mathrm{REV})$.
As shown in Fig. 12, when sliding velocities increased from $25 \mathrm{REV}$ to $50 \mathrm{REV}$ and $100 \mathrm{REV}$, the friction coefficients of pure epoxy samples increased from 0.5917 to 0.582 and 0.672 , The friction coefficient of composites metal microcapsules-10 $\mathrm{wt} \%$ also increased slightly from 0.559 to 0.569 and 0.596 the friction coefficient of composites metal microcapsules-30 $\mathrm{wt} \%$ was increased trend from 0.507 to 0.557 and 0.566 , and the friction coefficient of composites polymer microcapsules-10 $\mathrm{wt} \%$ increased slightly from 0.071 to 0.086 and 0.09 , respectively. The friction coefficients of all samples increased slightly under higher sliding velocities because a larger contact interface was produced under higher sliding velocities, increasing mechanical interlock. Also, higher temperatures were produced under higher velocities, and it softened the polymeric matrix for more serious adhesion wear under faster sliding velocities. Although the liquid core from metal microcapsules was released to decrease friction coefficient of composites at higher sliding velocities, more metal shell was also worn into powder to absorb liquid core and therein higher friction coefficient. ${ }^{[4]}$ Even when metal microcapsules concentration was increased from $10 \mathrm{wt} \%$ to $30 \mathrm{wt} \%$, the friction coefficient of composites was improved very slightly. Besides, the friction coefficients of composites polymer 
microcapsules- $10 \mathrm{wt} \%$ were increased slightly. Although a massive liquid core was released into wear track as a lubricant, larger contact interfaces were produced under higher sliding velocities to increase friction coefficient by more mechanical interlock of two mating interfaces.

The concentrations of metal microcapsules influenced slightly the friction coefficient of composites. When the concentration of metal microcapsules was $10 \mathrm{wt} \%$, the friction coefficient of samples was decreased by $5.6 \%$ (25 REV), $2.2 \%$ (50 REV), and $11.3 \%$ (100 REV) comparing with pure epoxy samples. The minor decrease of friction coefficient was mainly because the metal shell tended to increase the friction coefficient of the matrix after being worn into powder. Moreover, the metal powder could absorb the HMDI, resulting in the loss of lubricating capability. When the concentration of metal microcapsules was increased from $10 \mathrm{wt} \%$ to $30 \mathrm{wt} \%$, the friction coefficient of epoxy composites decreased by $9.3 \%$ (25 REV), 2.1\% (50 REV), and 5\% (100 REV) comparing to pure epoxy samples. Although more liquid core was released, the amount of metal powder was also increased under higher microcapsules concentration. Therefore, metal microcapsules concentration influenced slightly the self-lubrication performance of epoxy composites.

In comparison, when $10 \mathrm{wt} \%$ of polymer microcapsules were formulated into epoxy resin, the friction coefficient of composites was decreased by $88 \%$ ( $25 \mathrm{REV}$ ), $85.3 \%$ (50 REV), and $86.5 \%$ (100 REV), respectively. The release of liquid HMDI decreased efficiently the friction coefficient of epoxy composites. Comparing with metal microcapsules, polymer microcapsules possessed better self-lubrication performance.

3.4.3 Influence of sliding velocity on the wear loss of composites

Besides friction coefficient, sliding velocities also influenced significantly the wear loss of composites including pure epoxy samples, composites polymer microcapsules-10 wt $\%$, composites metal microcapsules- $10 \mathrm{wt} \%$, and composites metal microcapsules-30 wt $\%$, and the wear loss was characterized in terms of wear width and wear depth, as shown in Fig. 13a and 13b.

Fig. 13a showed the wear width of samples as a function of sliding velocities. As shown in Fig. 13a, the wear width of samples increases from $0.87 \pm 0.04 \mathrm{~mm}$ (pure epoxy samples) to $1 \pm 0.06 \mathrm{~mm}$ and $1.21 \pm 0.04 \mathrm{~mm}$, from $0.86 \pm 0.06 \mathrm{~mm}$ (Composites metal microcapsules-10 $\mathrm{wt} \%$ ) to $0.94 \pm 0.9 \mathrm{~mm}$ and $1.29 \pm 0.04 \mathrm{~mm}$, from $0.81 \pm 0.03 \mathrm{~mm}$ (Composites metal microcapsules-30 $\mathrm{wt} \%$ ) to $0.9 \pm 0.05 \mathrm{~mm}$ and $1.16 \pm 0.05 \mathrm{~mm}$, along with from $0.35 \pm 0.03 \mathrm{~mm}$ (Composites polymer microcapsules- $10 \mathrm{wt} \%$ ) to $0.43 \pm 0.1 \mathrm{~mm}$ and $0.45 \pm 0.13 \mathrm{~mm}$ when sliding velocities were increased from $25 \mathrm{REV}$ to 50 REV and 100 REV, respectively. As shown in Fig. 13b, the wear depth of samples increases from $46.3 \pm 5.4 \mu \mathrm{m}$ (pure \%epoxy samples) to $58.2 \pm 4.2 \mu \mathrm{m}$ and $99.2 \pm 8.3 \mu \mathrm{m}$, from $40.7 \pm 2.7 \mu \mathrm{m}$ (Composites metal microcapsules-10 $\mathrm{wt} \%$ ) to $58.6 \pm 9.9 \mu \mathrm{m}$ and $99.3 \pm 7.3 \mu \mathrm{m}$, from $35.4 \pm 2.4 \mu \mathrm{m}$ (Composites metal microcapsules-30 wt\%) to $50.6 \pm 9.7 \mu \mathrm{m}$ and $92.2 \pm 11.2 \mu \mathrm{m}$, along with from $2.97 \pm 0.92 \mu \mathrm{m}$ (Composites polymer microcapsules-10 $\mathrm{wt} \%$ ) to $5.8 \pm 3 \mu \mathrm{m}$ and $8.9 \pm 4.4 \mu \mathrm{m}$ when sliding velocities increase from $25 \mathrm{REV}$ to $50 \mathrm{REV}$ and $100 \mathrm{REV}$, respectively. Normally, both wear width and wear depth of samples were increased under higher velocities, and the main reason was that samples experienced more friction laps under higher sliding velocities. When $10 \mathrm{wt} \%$ of metal microcapsules were embedded in epoxy resin, the wear loss including wear width and wear depth of composites metal microcapsules- $10 \mathrm{wt} \%$ was almost the same as that of pure epoxy samples, implied the metal microcapsules influenced slightly the wear loss under different sliding velocities. Although liquid core was released as a lubricant to retard wear of matrix, the metal shell of metal microcapsules was also worn into metal powder, which tended to increase the friction coefficient of epoxy composites.

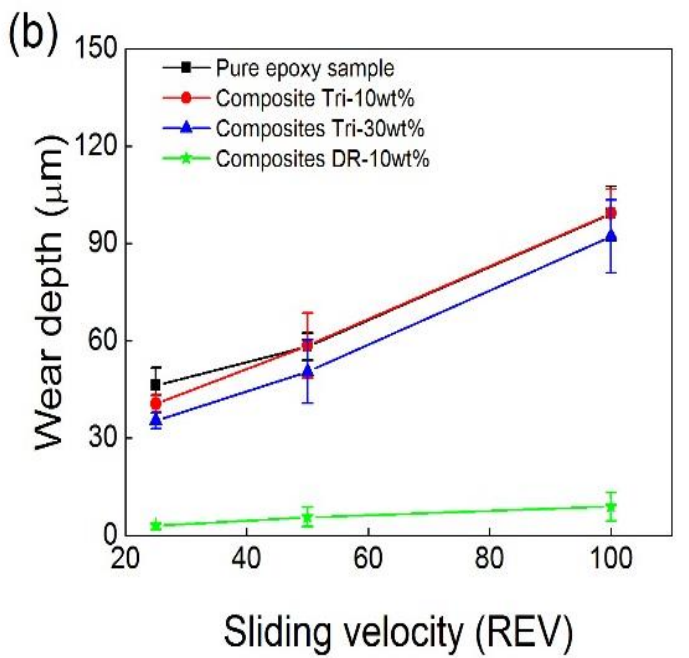

Fig. 13 The wear width (a) and depth (b) of pure epoxy samples, composites metal microcapsules -10 wt $\%$, composites metal microcapsules-30 wt $\%$, and composites polymer microcapsules-10 wt $\%$ as a function of sliding velocity (25 REV, $50 \mathrm{REV}$, and 100 REV). 


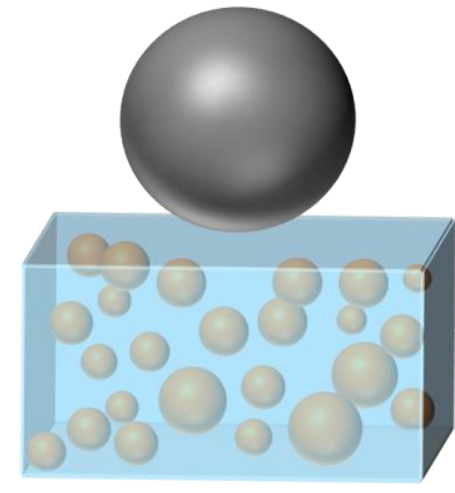

(a)

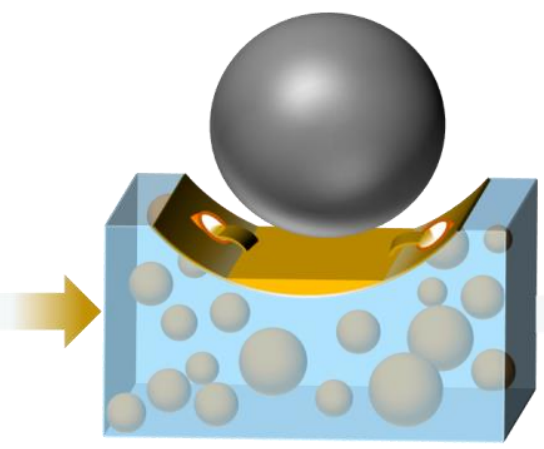

(b)

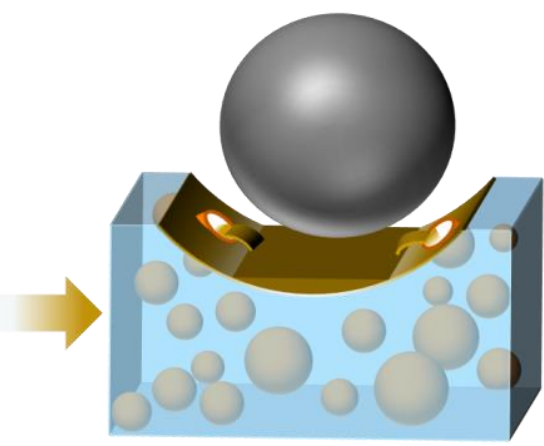

(c)

Fig. 14 (a) the surface of epoxy composites was worn by a steel ball; (b) the embedded microcapsules were broken and released isocyanate into the wear track, and (c) the isocyanate on the wear track was cured by surrounding moisture and lost lubricating capability.

Besides, the metal powders could also absorb the liquid HMDI due to its large specific areas. However, when metal microcapsules concentration was increased to $30 \mathrm{wt} \%$, the lubricating performance of metal microcapsules was improved slightly. Comparing with pure epoxy samples, the wear width of composites metal microcapsules-30 wt $\%$ decreased by $6.9 \%$ (25 REV), 13\% (50 REV), and 4.1\% (100 REV), while the depth decreased by $23.5 \%$ (25 REV), 13\% (50 REV), and 7\% (100 REV), respectively. The slight improvement of wear loss was mainly due to the increase of released liquid core resulting in better lubricating performance when epoxy composites contained more microcapsules.

The epoxy composites contained polymer microcapsules showed the slightest wear loss. Comparing with pure epoxy samples, the wear width of composites polymer microcapsules- $10 \mathrm{wt} \%$ decreased by $59.8 \%$ (25 REV), $57 \%$ ( $50 \mathrm{REV})$, and $62.8 \%$, while the wear depth decreased by $93.6 \%$ (25 REV), 90\% (50 REV) and 90.3\% (100 REV), respectively. Such an obvious improvement of wear loss was mainly resulted from the release of massive liquid core on the wear tracks during the friction process.

Therefore, it was reasonable to conclude that polymer microcapsules showed more outstanding self-lubrication performance than metal microcapsules in an epoxy matrix.

\subsection{Mechanism of self-lubricating coatings}

Based on the experimental data, the self-lubricating mechanism was proposed. When a steel ball wore the surface of composites (Fig. 14a), the embedded microcapsules were broken during the wear process (Fig. 14b) and released isocyanate into the wear track to lubricate the wear process, resulting in the decrease of friction coefficient and wear loss. When the isocyanate was cured into polymer films by surrounding moisture, the isocyanate lost the lubricating capability (Fig. 14c). When the polymer films were worn out by the friction process, the new microcapsules would be further broken and start over the lubricating process.
Besides, the shell material influenced significantly the lubricating performance of microcapsules. The metal shell could be worn into metal powder on the wear track, which could absorb the isocyanates due to the large specific area, resulting in the loss of self-lubricating capability. In comparison, the polymer microcapsules could not form massive powder on the wear track and therein showed outstanding self-lubricating performance in epoxy composites. Therefore, although the metal microcapsules could boost the mechanical properties of epoxy composites, the selflubricating performance of composites was weakened greatly by the metal shell.

\section{Summary}

Both metal microcapsules and polymer microcapsules showed obvious core-shell structures. Shell strength influenced \%significantly the mechanical properties of the polymeric matrix. The compressive strength of epoxy composites containing metal microcapsules was higher than that of epoxy composites containing polymer microcapsules under the same concentrations. Besides, the compressive modulus of composite remained stable relatively with the increase of metal microcapsules concentration, while it decreased fast under higher polymer microcapsules concentration. Polymer microcapsules possess outstanding self-lubricant performance in epoxy resin. Comparing with pure epoxy samples, the friction coefficient of composites polymer microcapsules$10 \mathrm{wt} \%$ decreased by higher than $80 \%$ under various normal loads and sliding velocities, and the wear loss was also improved very outstandingly under different conditions. Comparing with the pure epoxy samples, the friction coefficient of composites metal microcapsules- $10 \mathrm{wt} \%$ decreased by less than $10 \%$ under various normal loads and sliding velocities. More interesting, the wear loss of composites metal microcapsules- $10 \mathrm{wt} \%$ was higher than that of pure epoxy samples. Moreover, the increase of metal microcapsules concentration (metal microcapsules-30 wt\%) 
influenced slightly the friction coefficient and wear loss of composites under different conditions. The strength of epoxy composites containing metal microcapsules and polymer microcapsules was $70.0 \pm 1.2 \mathrm{MPa}$ and $39.7 \pm 0.8 \mathrm{MPa}$ under the concentration of $30 \mathrm{wt} \%$, and the modulus of respective composites was $2.36 \pm 0.01 \mathrm{GPa}$ and $1.09 \pm 0.06 \mathrm{GPa}$. The friction coefficient of composites containing metal microcapsules and polymer microcapsules was mainly distributed within $0.5 \sim 0.6$ and below 0.1 under different normal loads and sliding velocities.

\section{Acknowledgments}

Support from General Program of Science and Technology Development Project of Beijing Municipal Education Commission (KM202010005004), and the National Natural Science Foundation of China (52002006) are gratefully acknowledged.

\section{Conflict of Interest}

There is no conflict of interest.

\section{Supporting Information}

Not applicable.

\section{References}

[1] H. S. Ryu, J. K. Singh, H.S. Lee, M. A. Ismail, W. J. Park, Constr. Build. Mater., 2017, 133, 387-396, doi: 10.1016/j.conbuildmat.2016.12.086.

[2] A. Goyal, H. S. Pouya, E. Ganjian, P. Claisse, ARAB. J. Sci. Eng., 2018, 43, 5035-5055, doi: 10.1007/s13369-018-3303-2.

[3] R. Selvaraj, M. Selvaraj, S. Iyer, Prog. Org. Coat., 2009, 64, 454-459, doi: 10.1016/j.porgcoat.2008.08.005.

[4] S. Bahadur, D. Gong, Wear, 1992, 158, 41-59, doi: 10.1016/0043-1648(92)90029-8.

[5] E. N. Brown, M. R. Kessler, N. R. Sottos, S. R. White, S. R. 2003, 20, 719-730, doi: 10.1080/0265204031000154160.

[6] G. West, J. Senior, Tribology, 1973, 6, 269-275, doi: 10.1016/0041-2678(73)90177-2.

[7] Z. Z Zhang, W. M. Liu, Q. J. Xue, J. Appl. Polym. Sci., 2001, 80, 1891-1897, doi: 10.1002/app.1286.

[8] Q. B. Guo, K.T. Lau, B. F. Zheng, M. Z. Rong, M.Q. Zhang, Macromol. Mater. Eng., 2009, 294, 20-24, doi: 10.1002/mame.200800257.

[9] D. Sun, H. Zhang, X. Z. Tang, J. Yang, Polymer, 2016, 91, 3340, doi: 10.1016/j.polymer.2016.03.044.

[10] D. Sun, J. An, G. Wu, J. Yang, J. Mater. Chem. A, 2015, 3, 4435-4444, doi: 10.1039/C4TA05339G.

[11] D. Sun, Y. B. Chong, K. Chen, J. Yang, Chem. Eng. J., 2018, 346, 289-297, doi: 10.1016/j.cej.2018.04.046.

[12] N. Khun, D. Sun, M. Huang, J. Yang, C. Yue, Wear, 2014, 313, 19-28, doi: 10.1016/j.wear.2014.02.011.

[13] M. Ghorbani, H. Ebrahimnezhad-Khaljiri, R. Eslami-Farsani, H. Vafaeenezhad, Surf. Interf., 2021, 23, 100998, doi: 10.1016/j.surfin.2021.100998.

[14] N. Khun, H. Zhang, J. Yang, E. Liu, Wear, 2012, 296, 575-
582, doi: 10.1016/j.wear.2012.07.029.

[15] J. Yang, M.W. Keller, J. S. Moore, S. R. White, N. R. Sottos, Macromolecules, 2008, 41, 9650-9655, doi: 10.1021/ma801718v. [16] H. Zhang, X. Zhang, C. Bao, X. Li, D. Sun, F. Duan, K. Friedrichh J. Yang, J. Mater. Chem. A, 2018, 6, 24092-24099, doi: 10.1039/C8TA08324J.

[17] E. N. Brown, M. R. Kessler, N. R. Sottos, S. R. White, J. Microencapsul., 2003, 20, 719-730, doi: 10.3109/02652040309178083.

[18] H. Zhang, X. Zhang, C. Bao, X. Li, F. Duan, K. Friedrich, J. Yang, Chem. Mater., 2019, 31, 2611-2618, doi: 10.1021/acs.chemmater.9b00398.

[19] H. Zhang, X. Zhang, Y. B. Chong, J. Peng, X. Fang, Z. Yan, b. Liu, and J. Yang, J. Phys. Chem. C, 2019, 123, 22413-22423, doi: 10.1021/acs.jpcc.9b06544.

[20] H. Zhang, X. Zhang, Q. Chen, X. Li, P. Wang, E. H. Yang, F. Duan, X. Gong, Z. Zhang, J. Yang, J. Mater. Chem. A, 2017, 5, 22472-22479, doi: 10.1039/C7TA04904H.

[21] M.M. Caruso, B. J. Blaiszik, H. Jin, S. R. Schelkopf, D. S. Stradley, N. R. Sottos, S. R. White and J. S. Moore, ACS Appl. Mater. Inter., 2010, 2, 1195-1199, doi: 10.1021/am100084k.

[22] M.W. Patchan, B.W. Fuller, L. M. Baird, P. K. Gong, E.C. Walter, B. J. Vidmar, I. Kyei, Z. Xia, J. J. Benkoski, ACS Appl. Mater. Inter., 2015, 7, 7315-7323, doi: 10.1021/acsami.5b00494. [23] P. D. Tatiya, R. K. Hedaoo, P. P. Mahulikar, V. V. Gite, Ind. Eng. Chem. Res., 2013, 52, 1562-1570, doi: 10.1021/ie301813a. [24] H. Zhang, P. Wang, J. Yang, Compos. Sci. Technol., 2014, 94, 23-29, doi: 10.1016/j.compscitech.2014.01.009.

[25] D. Sun, H. Zhang, X. Zhang, J. Yang, ACS Appl. Mater. Inter, 2019, 11, 9621-9628, doi: 10.1021/acsami.9b00827.

[26] F. Svahn, A. Kassman-Rudolphi, E. Wallen, Wear, 2003, 254, 1092-1098, doi: 10.1016/S0043-1648(03)00341-7.

[27] P. L. Menezes, S. V. Kailas, Wear, 2009, 267, 1534-1549, doi: 10.1016/j.wear.2009.06.003.

\section{Author information}

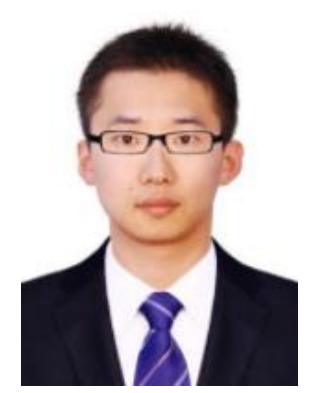

Dawei Sun obtained his Dr. Eng. from Nanyang Technological University in 2017. After that, he joined Beijing University of Technology and has been working as an lecture. His research focuses on the preparation and investigation of novel microcapsules, self-healing materials, and molecular dynamics.

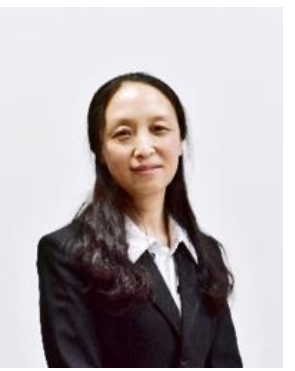

Cui Suping is the professor of MSE at Beijing University of Technology. Prof. Cui is the acadamic leader of inorganic materials department of MSE at BJUT, and she was awarded the National Project for Millions of Talents and Beijing Scholars, and so on. Prof. Cui has been in charge of some major 
science and technology projects of china, and was honored the second prize of national science and technology progress.

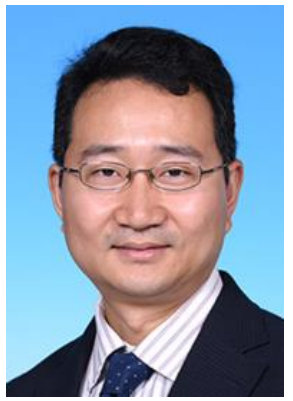

Jinglei Yang obtained his Bachelor and Master degrees from University of Science and Technology of China in 1999 and 2002, respectively, and Ph.D. degree from the Institute for Composite Materials at Technical University of Kaiserslautern, Germany in 2006. He was a PostDoc Research Associate in Beckman Institute at University of Illinois at Urbana-Champaign from 2006 to 2008. He joined Nanyang Technological University (NTU) as an Assistant Professor from 2008 to 2016. He received the Wilfried Ensinger Award supported by the Scientific Alliance of the University Professors of Polymer Technology (WAK) Germany (2008), Koh Boon Hwee Scholars Inspirational Teaching Award from NTU (2013), and Distinguished Young Investigator of China Frontiers of Engineering Award from Chinese Academy of Engineering (2019). He was included in the top $1 \%$ list of global materials scientists assessed by standardized citation metrics (2020) and named a Fellow of the Royal Aeronautical Society (2021) and the Royal Society of Chemistry (2021).

Publisher's Note Engineered Science Publisher remains neutral with regard to jurisdictional claims in published maps and institutional affiliations. 